\title{
EFFECT OF LAND CREATION ON REGIONAL ECOLOGICAL ENVIRONMENT: A CASE STUDY FOR LANZHOU CITY, CHINA
}

\author{
SHI, Y. F. ${ }^{1 *}-$ MA, C. ${ }^{1}-$ KONG, D. J. ${ }^{2}-$ ZHAO, J. ${ }^{1}$ \\ ${ }^{1}$ College of Geography and Environment Science, Northwest Normal University \\ Lanzhou, Gansu Province 730070, China \\ ${ }^{2}$ School of Foreign Languages, Lanzhou Jiaotong University \\ Lanzhou, Gansu Province 730070, China \\ *Corresponding author \\ e-mail: shiyfgis@126.com
}

(Received $21^{\text {st }}$ Jan 2019; accepted $27^{\text {th }}$ Feb 2019)

\begin{abstract}
With the accelerating process of urbanization, the contradiction between the shortage of land resources and the expansion of cities has become increasingly prominent. Many cities have expanded the area of development by "cutting mountains and building land". Taking Lanzhou city of China, a typical valley-type city as the study area, land use change data obtained from remote sensing imagery in 1995, 2000, 2005, 2010, and 2015 were quantified by land use transfer matrix, land use change intensity index, ecosystem service value, and regional eco-environmental quality index method. The study on the characteristics of land use change and its impact on the ecological environment in Lanzhou City shows that the land use change in Lanzhou City during the period of 1990 to 2015 years is mainly reflected by the decrease of cultivated land and grassland, the increase in construction land and unused land area; The quality of eco-environment in Lanzhou City was negative developed from 1990 to 2015. The spatial expansion caused by urbanization had the most profound impact on land use types; the minimum value of eco-environmental index of all counties in Lanzhou City appeared in 2015, and Grassland and Farmland occupied by a large amount of construction land is the main reason for the deterioration of ecological environment quality. Based on the study, we expected to provide reference for the development and construction, and ecological environment protection of similar areas, especially the cities with extremely shortage of land resources such as the typical river-valley cities in the future development.
\end{abstract}

Keywords: land creation, ecological environmental effect, land use, TM image, Lanzhou City of China

\section{Introduction}

The fundamental national condition that China has Limited Farmland per Capita has led to a strong contradiction between supply and demand for land resources. Nowadays, the process of urbanization in our country is accelerating, and cities are rapidly expanding. However, limited land resources and urban expansion space have limited the expansion of cities. Especially in the valley-cities, the expandable area is relatively limited due to the restrictions of the terrain. Under the background of increasingly conspicuous contradiction between limited land resources, increasing population and land use demand, some cities in our country carry out the project of "Bulldoze Mountains to Build New City" to expand the urban area, thus obtaining better development space. For example, Yan'an expands the scale of the city through the method of "Foundation in the mountains" and builds a Yan'an New Area (Cui, 2015); the "industry terrace" project was implemented in Fujian, Guizhou, etc. (Huang, 2014; Jiang et al., 2007). The main method is to combine "truncating the mountain" and filling land with flat land in order to expand the area; the new district of Lanzhou and Gaolan county in Gansu Province have expanded the area of development by "truncating the 
mountain". However, various scholars have different opinions on whether the "Bulldoze Mountains to Build New City" is feasible or not. Cui (2015) believes that the construction of Yan'an New District will continue to expand land for urban construction, at the same time, it causes changes in land use types, destruction of vegetation resources and ecological environment. Li et al. (2014) considered that the "cutting the mountain and building the city" project was not mature in terms of economy, technology, and ecological protection. Liu and Li (2014) considered that the implementation of the government's plan, "Cutting off hilltops and moving mountains to build city in Yan'an", is feasible and provides references for other cities. That because detailed planning, hydrology and water resources, have demonstrated from all sides of ecology by experts.

"Bulldoze Mountains to Build New City" will cause changes in the land use types. Changes in land use types ( $\mathrm{Li}$ et al., 2017; Tan et al., 2010) will have an impact on the regional ecological environment. The quality of the ecological environment will directly affect human well-being and the sustainable development of the region (Chang et al., 2017; Ma et al., 2015; Liu et al., 2005, 2009; Terefe et al., 2017). Domestic and foreign scholars have studied the impact of changes in land use types on the value of ecological services. For example, such as Terefe et al. (2017) believed that the reduction of forest land in Ethiopia has resulted in huge losses in ecosystem service value; Lawler et al. (2014) studied land use change in the United States. The impact of changes on ecosystem services suggests that changes in land use have promoted the fixation of carbon but led to the destruction of ecological environment. Xie et al. (2008) studied the land use changes in the suburbs of Tongchuan City on the eco-environment with the value of ecosystem services as indicators. Zhou et al. (2017) studied the effect of ecosystem service value of valley-city in Lanzhou, and concluded that the invading of farmland ecosystems by land for urban construction led to a drastic decline in ecosystem service value in Qinwangchuan basin. However, ecosystem service value is used to measure the quality of the ecological environment as an important indicator (Rong et al., 2017; Zhang et al., 2017; Hu et al., 2008).

As a typical valley-city, Lanzhou City has limited land resources, urban development is restricted, and the contradiction between growing population and demand for land is becoming increasingly prominent. In the past two decades, many cities such as Qinwangchuan and the new district of Lanzhou have carried out a number of "Bulldoze Mountains to Build New City projects", thereby expanding the urban land area. Therefore, the thesis uses Lanzhou City as an object of study to use the Landsat image data from 1990 to 2015 to analyze the characteristics of spatio-temporal changes in land use, and estimate the value of ecosystem services, continue to evaluate the impact of land use changes on ecology caused by "Bulldoze Mountains to Build New City".

\section{Material and methods}

\section{Background of the study area}

Lanzhou City, the capital of Gansu Province, is the political, economic and cultural center of Gansu Province and it is also an important central city in the northwestern China. It is located in the upper reaches of the Yellow River and is located at longitude $102^{\circ} 36^{\prime}-104^{\circ} 34^{\prime} \mathrm{E}$ and latitude $35^{\circ} 34^{\prime}-37^{\circ} 07^{\prime}$ (Fig. 1), with an average elevation of $1500 \mathrm{~m}$. It belongs to the loess hilly and gully region, temperate semi-arid continental monsoon climate, and large temperature difference between day and night, less 
precipitation (Guo et al., 2016). Lanzhou is an important support for the Western Long Hai-Lan Xin Economic Zone. The core of the upper Yellow River economy is mainly composed 34 towns and 27 villages. It currently governs five districts such as Chengguan District, Qilihe District, Anning District, Xigu District, and Honggu District and three counties including Yuzhong County, Gaolan County and Yongdeng County The total land area of Lanzhou City is 1311.9 thousand $\mathrm{hm}^{2}$. Due to the constraints of the canyon topography and the two mountains in the north and the south, Lanzhou's urban space development is greatly constrained. The geographical space is relatively narrow and its integrity is poor. It is a typical valley-city in China (Zhang et al., 2013). The human settlement environment formed by this influence is special.

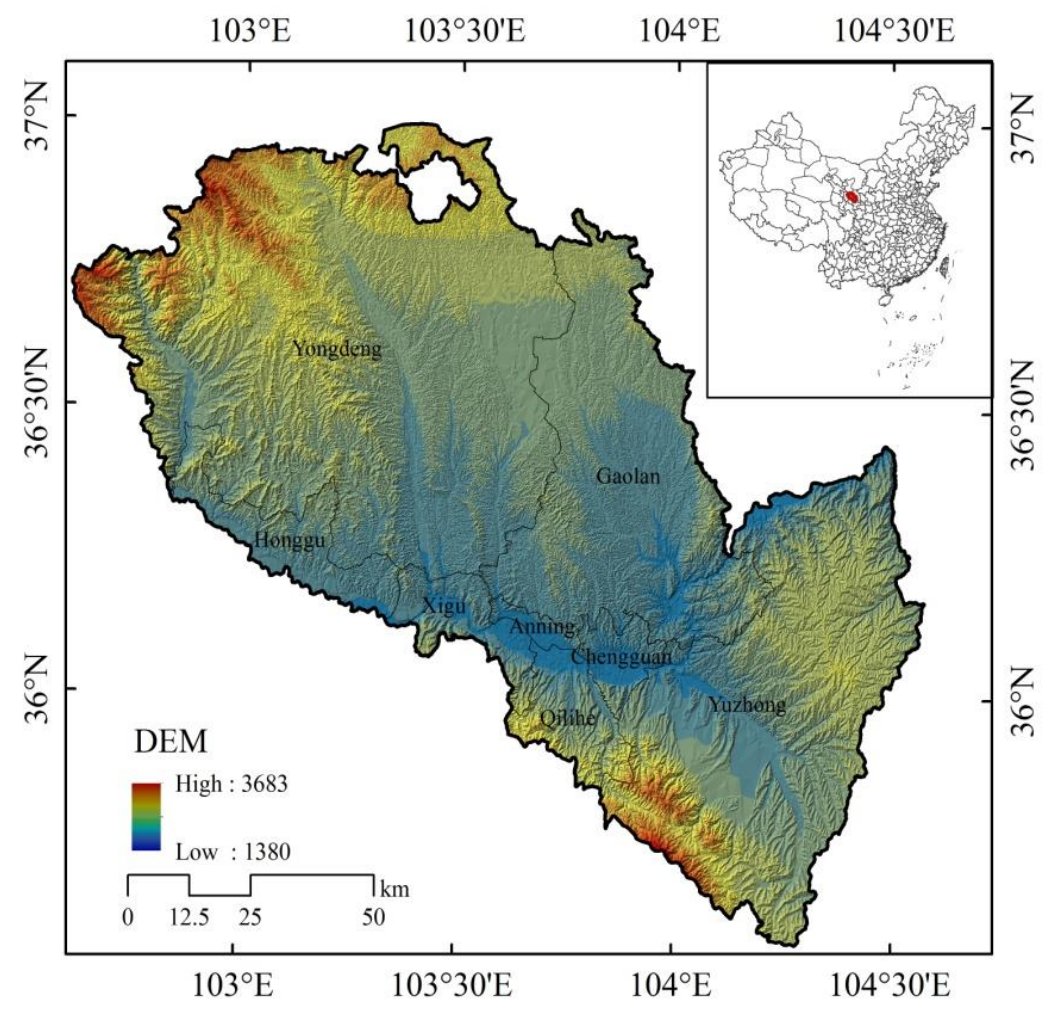

Figure 1. The location of study area

\section{Data sources and processing}

The research data used in this paper includes:

Remote Sensing Data: Landsat remote sensing images of Lanzhou City were selected in 1990, 1995, 2000, 2005, 2010 and 2015. The coordinates are 130/35, 131/34, and $131 / 35$, and the spatial resolution is $30 \mathrm{~m}$. All these data are from Geospatial Data Cloud (http://westdc.westgis.ac.cn).

Through radiation correction and FLAASH atmospheric correction, the processed remote sensing images were stitched and cropped to obtain remote sensing images in the study area from 1990 to 2015. By classification, the land use type map was obtained. In this study, the overall accuracy (OA), and another discrete multivariate index KAPPA (K) coefficient are used in accuracy assessments. The OA and $\mathrm{K}$ statistics can be calculated as Equations 1 and 2, respectively (Wei et al., 2010): 


$$
\begin{gathered}
\mathrm{OA}=\frac{\sum_{i=1}^{k} n_{i i}}{n} \\
\mathrm{~K}=\frac{n \sum_{i=1}^{k} n_{i i}-\sum_{i=1}^{k} n_{i+} n_{+i}}{n^{2}-\sum_{i=1}^{k} n_{i+} n_{+i}}
\end{gathered}
$$

where, $\mathrm{n}$ is the total number of observations; $k$ is the number of rows in the matrix, and $n_{i i}$ is the number of observations in row $i$ and column $i ; n_{i+}$ and $n_{+i}$ are the total numbers of pixels in $i$-th row and $i$-th column, respectively. The results of statistics and accuracy analysis are shown in Table 1.

Table 1. The classification supervision accuracy evaluation

\begin{tabular}{c|c|c|c|c|c|c}
\hline Year & $\mathbf{2 0 1 5}$ & $\mathbf{2 0 1 0}$ & $\mathbf{2 0 0 5}$ & $\mathbf{2 0 0 0}$ & $\mathbf{1 9 9 5}$ & $\mathbf{1 9 9 0}$ \\
\hline Kappa coefficient & 0.8699 & 0.8384 & 0.8248 & 0.8735 & 0.9024 & 0.9231 \\
Overall accuracy & $89.38 \%$ & $90.16 \%$ & $85.96 \%$ & $91.25 \%$ & $92.25 \%$ & $85.59 \%$ \\
\hline
\end{tabular}

From Table 1, we can see that the classification accuracy of land use types in Lanzhou City during the period from 1990 to 2015 is all above $85.5 \%$, which satisfies the accuracy requirements for follow-up studies.

Boundary data: National Geographic Center released.

\section{Research methods}

\section{Land use change intensity index}

The land use intensity index refers to the change in certain land-use types per unit area in the study area during a certain period of time. The land use change index (Xie et al., 2008) is calculated as Equation 3:

$$
\mathrm{K}_{i}=\frac{U_{\mathrm{a} i}}{U_{\mathrm{b} i}} \times \frac{1}{T} \times 100 \%
$$

where $\mathrm{K}_{i}$ denotes the $i$-th land use type change intensity index in the study area, $\mathrm{U}_{\mathrm{a} i}$ denotes the $i$-th land use type area in the initial stage of the study period, $\mathrm{U}_{\mathrm{b} i}$ denotes the $i$-th land use type area in the end of the research period, and $\mathrm{T}$ denotes the initial period of the study and the end of the study period. The time is apart and the unit is year.

\section{Calculation of ecological service value}

Xie et al. (2005) divided China's ecosystem services into nine categories such as climate regulation, water conservation, and food production, and formulated a table of ecological service values per unit area of different terrestrial ecosystems in China to calculate the ecological service value of the research area in different periods. The formula is as Equation 4: 


$$
\mathrm{ESV}=\sum_{i=1}^{n} A_{i} \times V C_{i}
$$

ESV is the total value of ecological services of different land-use types (yuan), $i$ refers to land-use types, $\mathrm{A}_{i}$ refers to the area of the $i$-th land-use type in the study area $\left(\mathrm{hm}^{2}\right)$, and $\mathrm{VC}_{i}$ is the unit ecological service value of the $i$-th land-use type (Yuan $/ \mathrm{hm}^{2} \cdot \mathrm{a}$ ).

\section{Eco-environmental quality index}

Taking into consideration the ecological environment quality and area ratio of land use types in various regions, the eco-environmental index are used to quantitatively characterize the overall situation of the ecological environment quality in a certain region. The expression (Zhang et al., 2018) is as Equation 5:

$$
\mathrm{EV}_{t}=\frac{\sum_{i=1}^{n} A_{i} C_{i}}{\sum_{i=1}^{n} A_{i}}
$$

where $A_{i}, C_{i}$ is the area and eco-environmental index of the $i$-th land-use type in the period $t$, and $n$ is the number of land-use types in the area.

\section{Results and discussion}

\section{Analysis of land use change}

(1) Overall land use change from 1990 to 2015

Based on the remote sensing imagery data from 1990 to 2015, using a combination of supervised classification and artificial visual interpretation, the land use type map of Lanzhou was interpreted, as shown in Figure 2.

The overall classification accuracy of different periods is between 85.59 and $92.25 \%$, which meets the research needs. Overall, in the past 20 years, the land use structure in Lanzhou City underwent significant changes, mainly reflected in the increase in construction land and unused land, and the corresponding reduction in the area of cultivated land and grassland. From the point of view of spatial distribution, the increased construction land mainly shows two situations of agglomeration and scattered distribution. The increased construction land is mainly distributed in Gaolan County and Yongdeng County, that is, the construction of Lanzhou New District in December 2010 is consistent; The border between Anning District and Gaolan County is mainly the construction of Poly Xiuling Mountain, which is in line with the situation of the field investigation. Judging from the time series, the land for construction increased from 1990 to 2015 . With 2010 as the demarcation point, the area of construction land in 2015 increased significantly.

In order to further study the characteristics of land use structure in Lanzhou City from 1990 to 2015, the area and proportion of each type of land use were calculated separately. The results are shown in Table 2. 

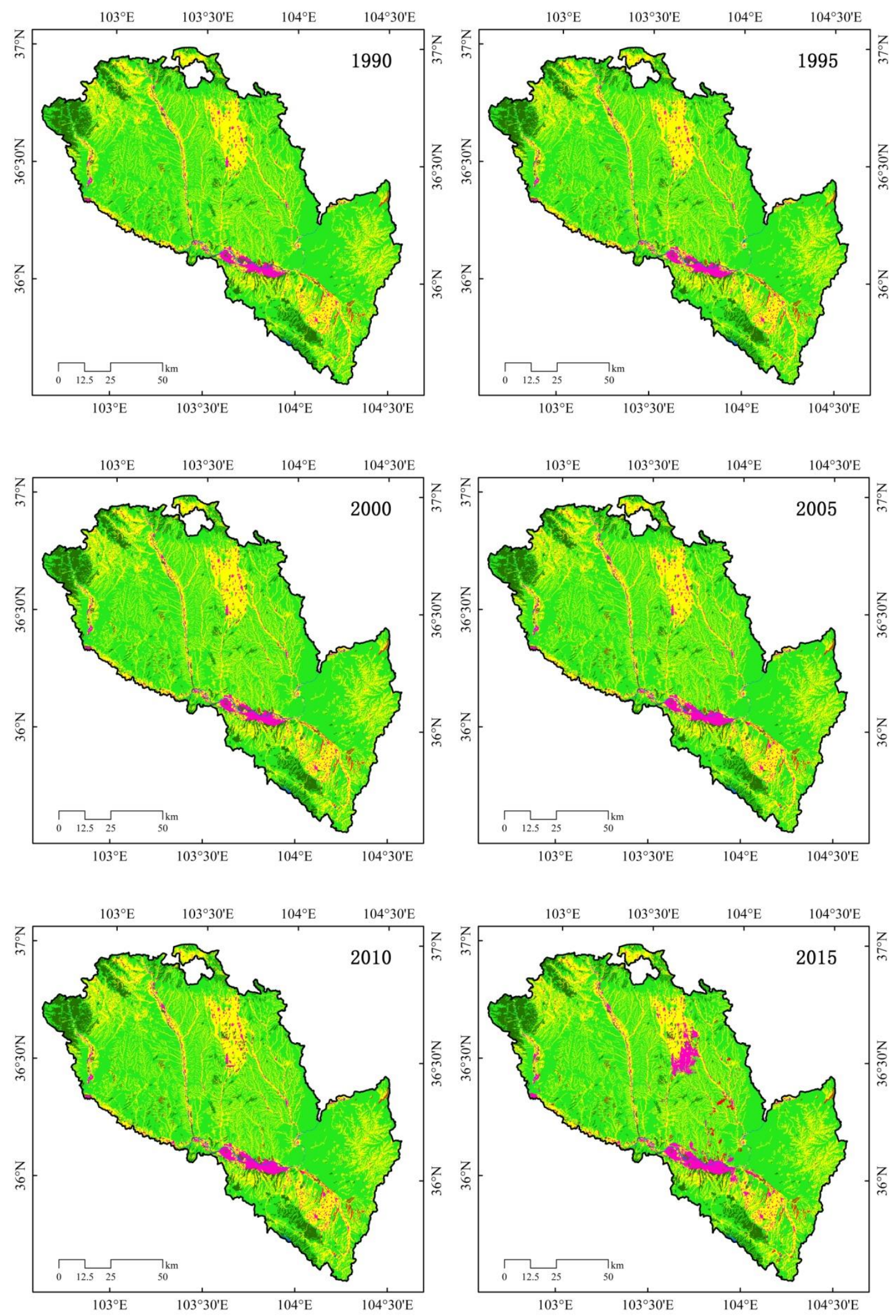

Legend

Forestland $\square$ Farmland $\square$ Grassland $\square$ Water area $\square$ Construction land $\square$ Unused land $\square$ Administrative divisions

Figure 2. Spatial distribution of land use types in Lanzhou city during 1990-2015 
Table 2. Land use structural feature of Lanzhou city during 1990-2015 (unit: $\mathrm{km}^{2}$ )

\begin{tabular}{c|c|c|c|c|c|c|c}
\hline \multirow{2}{*}{ Year } & & Farmland & Forestland & Grassland & Water area & $\begin{array}{c}\text { Construction } \\
\text { land }\end{array}$ & $\begin{array}{c}\text { Unused } \\
\text { land }\end{array}$ \\
\hline \multirow{2}{*}{1990} & Area $\left(\mathrm{km}^{2}\right)$ & 3853.51 & 900.91 & 8012.09 & 68.71 & 315.07 & 52.62 \\
& Proportion $(\%)$ & 29.19 & 6.82 & 60.68 & 0.52 & 2.39 & 0.40 \\
\hline \multirow{2}{*}{1995} & Area $\left(\mathrm{km}^{2}\right)$ & 3841.26 & 901.55 & 8007.88 & 69.38 & 328.75 & 54.08 \\
& Proportion $(\%)$ & 29.09 & 6.83 & 60.65 & 0.53 & 2.49 & 0.41 \\
\hline \multirow{2}{*}{2000} & Area $\left(\mathrm{km}^{2}\right)$ & 3850.19 & 904.19 & 7987.62 & 68.10 & 340.19 & 52.62 \\
& Proportion $(\%)$ & 29.16 & 6.85 & 60.50 & 0.52 & 2.58 & 0.40 \\
\hline \multirow{2}{*}{2005} & Area $\left(\mathrm{km}^{2}\right)$ & 3816.61 & 899.11 & 7993.48 & 68.17 & 369.81 & 55.73 \\
& Proportion $(\%)$ & 28.91 & 6.81 & 60.54 & 0.52 & 2.80 & 0.42 \\
\hline \multirow{2}{*}{2010} & Area $\left(\mathrm{km}^{2}\right)$ & 3788.53 & 918.96 & 7993.81 & 68.39 & 377.95 & 55.26 \\
& Proportion $(\%)$ & 28.69 & 6.96 & 60.55 & 0.52 & 2.86 & 0.42 \\
\hline \multirow{2}{*}{2015} & Area $\left(\mathrm{km}^{2}\right)$ & 3642.95 & 909.63 & 7917.97 & 70.04 & 558.40 & 103.91 \\
& Proportion $(\%)$ & 27.59 & 6.89 & 59.97 & 0.53 & 4.23 & 0.79 \\
\hline \multirow{2}{*}{$1990-$} & Net variable $\left(\mathrm{km}^{2}\right)$ & -210.56 & 8.72 & -94.12 & 1.33 & 243.33 & 51.29 \\
2015 & Change rate $(\%)$ & -1.6 & 0.07 & -0.71 & 0.01 & 1.84 & 0.39 \\
\hline
\end{tabular}

From Table 2, we can see that during the period from 1990 to 2015, grassland was the main type of land use in Lanzhou, accounting for about $60 \%$ of the total area; in 2005, as the boundary, it decreased first and then increased. In 2015, it decreased drastically, and its value was $94.12 \mathrm{~km}^{2}$. This is mainly caused by cutting mountains and land; arable land accounts for about $30 \%$ of the total area of land use. Since 2005, the area of cultivated land has been decreasing, which has decreased by nearly $210.56 \mathrm{~km}^{2}$ compared with that of 1990 . Construction land has been on an increasing trend. Compared with 1990, it has increased by $243.33 \mathrm{~km}^{2}$ with a rate of change of $1.84 \%$. Unused land and forest lands have been fluctuating. The change of Forest land was relatively small, while unutilized land increased nearly more than doubled in 2015 . That is mainly because the land, which used for construction has not been used yet, increased obviously after the bulldoze mountains.

\section{(2) Land use transfer characteristics and change intensity analysis}

From the spatial distribution and structural characteristics of land use, we can see that the land use structure of Lanzhou City has undergone significant changes from 1990 to 2015. Therefore, the land use transfer situation in Lanzhou City from 1990 to 2015 was analyzed. The results are shown in Table 3.

From Table 3, it can be seen that various types of land use types have changed from 1990 to 2015. The types of land converted into construction land are the unused land $<$ water area <woodland < grassland <cultivated land, and the area of water and unused land converted into construction land is $0.93 \mathrm{~km}^{2}$ and $0.3 \mathrm{~km}^{2}$ respectively; the area of cultivated land converted into construction land is $179.02 \mathrm{~km}^{2}$, accounting for $73.34 \%$ of the conversion area. The conflict of the shortage of land resources and the large area of land for urban construction leads to create land from mountains, which caused the majority of grassland and a little few of the farmland reduced. This is similar to Lanzhou New District and Poly Lingxiushan. The Country Garden, which is still under 
construction, has close ties with other construction projects. On the other hand, due to the need for the construction of educational resources, large-scale arable land has been lost, such as Pengjiaping, Qiujiawan and so on.

Table 3. Land use transfer matrix of Lanzhou city during 1990-2015 (unit: $\mathrm{km}^{2}$ )

\begin{tabular}{c|c|c|c|c|c|c|c}
\hline & \multicolumn{2}{|c}{$\mathbf{2 0 1 5}$} \\
\hline \multirow{1}{*}{1990} & Farmland & Forestland & Grassland & $\begin{array}{c}\text { Water } \\
\text { area }\end{array}$ & $\begin{array}{c}\text { Construction } \\
\text { land }\end{array}$ & $\begin{array}{c}\text { Unused } \\
\text { land }\end{array}$ \\
\cline { 2 - 8 } & Farmland & 3614.73 & 19.96 & 18.24 & 1.77 & 179.02 & 19.78 \\
& Forestland & 1.05 & 883.70 & 0.26 & 0.15 & 15.19 & 0.55 \\
& Grassland & 26.70 & 5.39 & 7898.95 & 0.52 & 48.63 & 31.89 \\
& Water area & 0.21 & 0.01 & 0.00 & 67.56 & 0.93 & 0.00 \\
& Construction land & 0.00 & 0.57 & 0.03 & 0.03 & 314.33 & 0.10 \\
& Unused land & 0.25 & 0.00 & 0.48 & 0.00 & 0.30 & 51.59 \\
\hline
\end{tabular}

In order to further reveal the changes of land use types in Lanzhou City during the past 25 years, the change intensity of land use types in Lanzhou City during different research periods was calculated and the results are shown in Table 4.

Table 4. The intensity of Land use change of Lanzhou city during 1990-2015 (unit: \%)

\begin{tabular}{c|c|c|c|c|c|c}
\hline Year & Farmland & Forestland & Grassland & Water area & Construction land & Unused land \\
\hline $1990-1995$ & -0.06 & 0.01 & -0.01 & 0.20 & 0.87 & 0.55 \\
$1995-2000$ & 0.05 & 0.06 & -0.05 & -0.37 & 0.70 & -0.54 \\
$2000-2005$ & -0.17 & -0.11 & 0.01 & 0.02 & 1.74 & 1.18 \\
$2005-2010$ & -0.15 & 0.44 & 0.00 & 0.07 & 0.44 & -0.17 \\
$2010-2015$ & -0.77 & -0.20 & -0.19 & 0.48 & 9.55 & 17.61 \\
$1990-2015$ & -0.22 & 0.039 & -0.047 & 0.08 & 3.09 & 3.90 \\
\hline
\end{tabular}

According to Table 4, from 1990 to 2015, the intensity index of land use change in forest land, water area, construction land, and unused land is positive, indicating that the overall area is increasing. In terms of different time periods, except for the intensity index of land use change during the period from 1995 to 2000, the rest is negative, indicating that the area of cultivated land has decreased during the past 15 years, and has decreased significantly from 2010 to 2015; The intensity index of construction land use change is positive, that is to say, the area of construction land in Lanzhou has increased at different degrees in the past 25 years. From 1990 to 2015, the positive value of the unexploited land use change index (19.34\%) was much greater than the negative value $(0.71 \%)$, and the unutilized land increased significantly. Most of the land obtained through the cut-to-earth land reclamation project has not yet been put into use in 2010-2015. Construction has led to a significant increase in unused land.

\section{Eco- services value measurement and analysis}

\section{(1) Land use transfer characteristics and change intensity analysis}

According to the research of Xie et al. (2005) in China's terrestrial ecosystem service value-equivalent factor table and correction factors of different provinces, the ecological 
service value of different land-use types in Lanzhou City is estimated, as shown in Table 5.

Table 5. The intensity of Land use change of Lanzhou city during 1990-2015 (unit: million yuan)

\begin{tabular}{c|c|c|c|c|c|c|c}
\hline Year & Forestland & Grassland & Farmland & Water area & $\begin{array}{c}\text { Construction } \\
\text { land }\end{array}$ & $\begin{array}{c}\text { Unused } \\
\text { land }\end{array}$ & Total value \\
\hline 1990 & 73156.2 & 215583.8 & 98958.4 & 11737.8 & 491.5 & 82.1 & 400009.7 \\
1995 & 73208.4 & 215470.4 & 98643.8 & 11852.5 & 512.8 & 84.4 & 399772.4 \\
2000 & 73422.5 & 214925.2 & 98873.2 & 11633.5 & 530.7 & 82.1 & 399467.1 \\
2005 & 73010.2 & 215083.0 & 98010.7 & 11645.5 & 576.9 & 86.9 & 398413.2 \\
2010 & 74622.5 & 215091.8 & 97289.8 & 11684.4 & 589.6 & 86.2 & 399364.2 \\
2015 & 73864.4 & 213051.2 & 93551.3 & 11965.7 & 871.0 & 162.1 & 393465.7 \\
\hline
\end{tabular}

From Table 5, we can see from the total value of ecosystem services, the total value of ecosystem services in Lanzhou City decreased and then increased from 1990 to 2015. The total value of ecosystem services continued to decline during 1990-2005, which was reduced by 1596.5 million yuan. From 2005-2010, the total value of ecosystem services showed an increasing trend. From 2010-2015, the total value of ecosystem services declined drastically 5898.5 million yuan.

From the single type of land use, the ESV for forest land is similar to the change in the total value of ecosystem services in Lanzhou City. From 1990 to 2005, there was a trend of "increase-decrease-increase", of which in 2010 and 1990, the forest ecosystem service value peaked in 1990 and 2010 at the highest and lowest values, which were 74622.5 million yuan and 73156.2 million yuan respectively. In the past 25 years, the ecosystem service value of grassland and farmland showed a decreasing trend. The maximum values all appeared in 1990, and the minimum values all appeared in 2015. This is mainly due to the large number of Bulldoze Mountains to Build New City projects destroyed in Lanzhou City. Grassland and farmland have resulted in a significant reduction in the area of these two types of land use, which has led to a reduction in the value of ecosystem services. Due to the needs of urban construction, the area of construction land continues to increase. As a result, the ecosystem service value of construction land continues to rise. The speed of land creation is faster than the speed of construction. As a result, the area of unused land continues to expand, leading to a significant increase in the value of ecosystem services of unused land from 2010 to 2015 .

\section{(2) Regional comprehensive ecological environmental quality change}

According to Equation 3, the eco-environmental indices of land use types in Lanzhou and its counties are calculated to analyze the impact of land use changes on the ecoenvironmental quality. The results are shown in Table 6.

From Table 6, we can see that the overall eco-environmental quality of Lanzhou City is basically stable, but it shows a downward trend. In addition to the increase trend from 2005 to 2010, the eco-environmental quality index of Lanzhou during the four periods of 1990-1995, 1995-2000, 2000-2005, and 2010-2015 both showed a downward trend. The ecological quality indices have been significantly reduced. The statistical analysis 
of the changes in eco-environmental index in all counties and counties of Lanzhou City in the past 25 years was the largest in Anning District, followed by Chengguan District, and Gaolan County ranked the third; the minimum eco-environmental index values of all counties appeared in 2015, including grassland and the large amount of cultivated land occupied by construction land is the main reason for the decline in the quality of the ecological environment.

Table 6. The ecological environment quality index of Lanzhou city during 1990-2015

\begin{tabular}{c|c|c|c|c|c|c}
\hline & $\mathbf{1 9 9 0}$ & $\mathbf{1 9 9 5}$ & $\mathbf{2 0 0 0}$ & $\mathbf{2 0 0 5}$ & $\mathbf{2 0 1 0}$ & $\mathbf{2 0 1 5}$ \\
\hline Chengguan District & 0.3283 & 0.3273 & 0.3273 & 0.3204 & 0.3218 & 0.3091 \\
Qilihe District & 0.3502 & 0.3508 & 0.3507 & 0.3493 & 0.3498 & 0.3465 \\
Anning District & 0.3145 & 0.3128 & 0.3128 & 0.3022 & 0.3021 & 0.2932 \\
Xigu District & 0.3499 & 0.3479 & 0.3482 & 0.3469 & 0.3463 & 0.3454 \\
Red Ancient District & 0.3341 & 0.3341 & 0.3339 & 0.3336 & 0.3333 & 0.3306 \\
Yongdeng County & 0.3491 & 0.3490 & 0.3490 & 0.3489 & 0.3495 & 0.3481 \\
Gaolan County & 0.3330 & 0.3331 & 0.3327 & 0.3330 & 0.3339 & 0.3280 \\
Yuzhong County & 0.3394 & 0.3392 & 0.3390 & 0.3387 & 0.3387 & 0.3378 \\
Lan'Zhou City & 0.3426 & 0.3425 & 0.3424 & 0.3421 & 0.3425 & 0.3401 \\
\hline
\end{tabular}

\section{Conclusions}

(1) From the land use type spatial distribution map, we can see that the area of construction land has increased significantly. It is mainly located in Yongdeng County and Gaolan County, and is used for the construction of Lanzhou New District and Poly Xiuling Mountain.

(2) In 2015, construction land and unused land increased rapidly. The project of "land creation" led to the conversion of large areas of farmland and grassland into construction land, which was mainly used for urban construction and educational resource construction.

(3) From the total value of ecosystem services, the total value of ecosystem services in Lanzhou City decreased and then increased from 1990 to 2015. From 2010 to 2015, the total value of ecosystem services declined drastically and its value was 5898.5 million yuan.

(4) During the period from 1990 to 2015, the overall eco-environmental quality in Lanzhou City was relatively stable, but overall it showed a deteriorating trend. Within the local area of each county, the quality of ecological environment changed significantly. Among them, the influence of cultivated land and grassland on the ecological environment quality played a leading role.

(5) This paper lacks the improvement research on the existing evaluation methods. How to consider other factors to the quantitative calculation of the ecological environment index, and accurately assess the effect of the land use changes on ecological environment. The influence of different scales and different land use classification systems on the evaluation results remains to be further studied in the future.

Acknowledgements. This work was funded by the National Natural Science Foundation of China $(41661084,41761083,41661035)$ and the project of Northwest Normal University (5007-355). 


\section{REFERENCES}

[1] Chang, Z. B., Qin, F., Han, Z. G., Lu, Y., Yu, Y. Y. (2017): Dynamic evaluation of ecoenvironmental quality in He'nan province based on RS and GIS. - Bulletin of Soil and Water Conservation 37: 132-137+345.

[2] Cui, Y. J. (2015): Study on the Benefit of Resources and Environment in Yan'an New Area. - Chang'an University, Xi'an.

[3] Guo, X. Y., Liu, X. L., Wang, L. G. (2016): Land use optimization in order to improve ecosystem service: a case of Lanzhou city. - Acta Ecologica Sinica 36: 7992-8001.

[4] Huang, R. (2014): The effect of land creation on atmospheric environment using numerical simulation in valley city: a case study for Lanzhou. - Lanzhou University, Lanzhou.

[5] Hu, H. B., Liu, W. J., Cao, M. (2008): Impact of land use and land cover changes on ecosystem services in Menglun, Xishuangbanna, Southwest China. - Environmental Monitoring and Assessment 146(1): 147-156.

[6] Jiang, H., Yin, Q., Luo, Y. X. (2007): Industry terrace-a new pattern of land use in China. - Agricultural Mechanization Research 05: 28-30+45.

[7] Lawler, J. J., Lewis, D. J., Nelson, E., Plantinga, A. J., Polasky, S., Withey, J. C., Helmers, D. P., Martinuzzi, S., Pennington, D., Radeloff, V. C. (2014): Projected landuse change impacts on ecosystem services in the United States. - Proc. Natl. Acad. Sci. USA 111: 7492-7497.

[8] Li, P. Y., Qian, H., Wu, J. H. (2014): Environment: accelerate research on land creation. - Nature 510: 29-31.

[9] Li, X., Chen, G. Z., Liu, X. P., Liang, X., Wang, S. J., Chen, Y. M., Pei, F. S., Xu, X. C. (2017): A new global land-use and land-cover change product at a 1-km resolution for 2010 to 2100 based on human-environment interactions. - Annals of the American Association of Geographers. DOI: 10.1080/24694452.2017.1303357.

[10] Liu, J. Y., Zhang, Z. X., Xu, X. L., Kuang, W. H., Zhou, W. C., Zhang, S. W., Li, R. D., Yan, C. Z., Yu, D. S., Wu, S. X., Jiang, N. (2009): Spatial patterns and driving forces of land use change in China in the early $21^{\text {st }}$ Century. - Acta Geographica Sinica 64: 14111420.

[11] Liu, Y. B., Li, R. D., Song, X. F. (2005): Analysis of coupling degrees of urbanization and ecological environment in China. - Journal Natural Resources 01: 105-112.

[12] Liu, Y. S., Li, Y. H. (2014): Environment: China's land creation project stands firm. Nature 511: 410.

[13] Ma, W. J., Pu, C. L., Su, L. L., Jiang, L. (2015): Analysis of impact of land use change on ecological environment in Changji city. - Tianjin Agricultural Sciences 21: 29-32+36.

[14] Rong, Y., Li, C., Xu, C., Yan, Y. (2017): Ecosystem service values and spatial differentiation changes during urbanization: a case study of Huanghua city. - Chinese Journal of Ecology 05: 1374-1381.

[15] Tan, K. C., Lim, H. S., MatJafri, M. Z., Abdullah, K. (2010): Landsat data to evaluate urban expansion and determine land use/land cover changes in Penang Island, Malaysia. - Environmental Earth Sciences 60(7): 1509-1521.

[16] Terefe, T., Feyera, S., Moges, K. (2017): The impact of land use/land cover change on ecosystem services in the central highlands of Ethiopia. - Ecosystem Services 47-54.

[17] Wei, Y. C., Tang, G. A., Yang, X. (2010): The Tutorial of Remote Sensing Digital Image Processing. - Science Press, Beijing, pp. 208-251.

[18] Xie, G. D., Xiao, Y., Zhen, L., Lu, C. X. (2005): Study on ecosystem services value of food production in China. - Chinese Journal of Eco-Agriculture 03: 10-13.

[19] Xie, H. X., Li, R., Ren, Z. Y., Yang, Q. K. (2008): Quantitative assessment of the effect on the eco-environment from LUCC in a region scale-a case in the city proper and the suburbs of Tongchuan. - Journal Natural Resources 03: 458-466. 
[20] Zhang, Q., Gao, S. F., Gao, C. Q., Wang, J. Z., Niu, L., Zhang, N. (2018): Ecological land of Pingdingshan city and its ecosystem services evolution over the past 20 years. Ecological Science 37: 159-168.

[21] Zhang, Y. J., Han, H. Q., Gao, H. J., Cai, G. P., Zhang, C. X. (2017): Coordination degree between ecosystem services value and land ecological security level in Zunyi. - Journal of Southwest Forestry University (Natural Science) 05: 141-146.

[22] Zhang, Z. B., Pan, J., Li, X. H. (2013): The spatial evolution and formation mechanism of population density in Lanzhou city over the past 30 years. - Scientia Geographica Sinica 33: 36-42.

[23] Zhou, W. X., Shi, P. J., Wang, Y. N., Liang, B. B., Tang, X. (2017): Effect of Ecosystem service values of river valley city: a case study of Lanzhou. - Arid Zone Research 01: 232-241. 